\section{A review of medicinal plants that modulate nitric oxide activity}

\author{
Jillian Borchard, 1 Lily Mazzarella, 1 \\ Kevin Spelman² \\ 1Department of Herbal Medicine, Tai \\ Sophia Institute; ${ }^{2}$ Laboratory of Clinical \\ Investigation, National Institute on \\ Aging/NIH, Baltimore, MD, USA
}

\section{Abstract}

Modulation of nitric oxide (NO) may offer novel approaches in the treatment of a variety of diseases, such as Alzheimer's, cardiovascular disease, and diabetes. A strategy in the modulation of NO expression may be through the use of herbal medicines. We surveyed medicinal plant research that utilized multicomponent extracts similar to what is used in clinical phytotherapy or in commerce, for demonstrated effects on NO activity. SciFinder Scholar, Pubmed, Web of Science, and BIOSIS were searched to identify human, animal, in vivo, ex vivo or in vitro research on botanical medicines, in whole or standardized form, that act on nitric oxide activity. iNOS was the most frequently investigated enzyme system and this system was up-regulated by many plant extracts, including, Chicorium intybus, Cocos nucifera, Echinacea purpurea, Euonymus alatus, Ixeris dentate, Oldenlandia diffusa, Rhinacanthus nasutus, and Sida cordifolia. Many plant extracts down-regulated iNOS, including Centella asiatica, Dichroa Febrifuga, Echinacea purpurea, Evolvulus alsinoides Fagonia cretica, Ginkgo biloba, Mollugo verticillata, Lactuca indica, Lithospermum erythrorhizon, Pueraria thunbergiana, and Taraxacum officinale. The eNOS system was stimulated by Eucommia ulmoides, Sida cordifolia, and Thymus pulegioides while Fagonia cretica, Rubia cordifolia and Tinospora cordifolia down-regulated nNOS. Given the activity demonstrated by many of these herbal medicines, the increasing awareness of the effects of nitric oxide on a wide variety of disease processes and the growing incidence of these conditions in the population, further study of medicinal plants on nitric oxide signaling may lead to novel therapies and further insight into human physiology.

\section{Introduction}

Well before Furchgott and Zawadzki ${ }^{1}$ proved the existence of a labile endothelium-derived relaxing factor (EDRF), nitric oxide (NO) had been found to be a potent vasodilator and to play a role in platelet aggregation. The eventual identification of $\mathrm{NO}$ as endothelial-derived relaxation factor led to the Nobel Prize for Ignarro, Furchgott and Murad. This was also the beginning of the recognition of NO as a key to not only vascular dynamics, but as a messenger molecule in a variety of tissues and organs. $^{2}$

NO is a crucial intra- and extra-cellular communicator, modulating ion channels and messaging dynamics. ${ }^{3}$ NO plays a pivotal role in physiological adaptation through its effects on vascular tone, proper neurotransmission, and proper immunological defense. ${ }^{4}$ Currently, NO is reported to act as a central modulator of functions ranging from neurotransmission, gene response and second-signal messaging. 5

As a neurotransmitter, NO plays a role in a number of processes including memory formation, sleep, neuropathologies and aging. 6,7 With regard to sleep, NO in the pontine tegmuntum enables the rapid eye movement stage. ${ }^{6}$ NO also demonstrates a neuroprotective role for both glial and neuronal cells. ${ }^{8}$ In the periphery, the network of non-adrenergic and non-cholinergic nerves operates through a nitric oxide-dependent mechanism regulating gastrointestinal, respiratory, and genitourinary tract functions. Additionally, erectile drugs act through neuronal generated NO. ${ }^{9}$

As an immunogenic messenger, substantial quantities of NO produced for host defense significantly influence the processes of immune system coordination, response, and inflammation. ${ }^{10}$ NO is generated by activated macrophages aiding in the response to infections, directly exerting antimicrobial activity, and affecting both innate and acquired immune function through the modulation of cytokine expression and leukocyte apoptosis. 10

The substrate for the production of NO is Larginine, a nitrogen rich amino acid shuttled through the L-arginine-nitric oxide pathway to meet the tissue specific enzyme, nitric oxide synthase (NOS). NOS releases picomoles of nitric oxide in response to receptor stimulation. ${ }^{11}$ NOS is unique, it is both a hemeprotein and flavoprotein. NOS includes three isoforms: neuronal NOS, named NOS1 or nNOS, inducible NOS, known as NOS2 or iNOS, and an endothelial NOS, known as NOS3 or eNOS.12 Two of the three identified isoforms of NOS (eNOS and iNOS) are found in endothelial cells. ${ }^{13}$ iNOS, which is integral to the inflammatory process and capable of high output of NO during inflammation, is inducible while nNOS and eNOS are constitutive. ${ }^{14}$ The three isoforms all require cofactors and prosthetic groups for activity, including FAD, FMN, heme, calmodulin, tetrahydrobiopterin and possibly thiols. ${ }^{12,15-17}$

Evidence suggests that a variety of diseases
Correspondence: Kevin Spelman, Herb Pharm, 20260 Williams Highway, Williams, OR 97544, USA. Tel. +1.541.846.6262 - Fax: +1.541.862.1641. E-mail: phytochemks@gmail.com

Key words: nitric oxide synthase, traditional medicine, traditional Chinese medicine, Ayurveda, herbs, immunomodulators, immune, medicinal plants.

Contributions: JB, LM reviewed accepted papers, wrote sections of the manuscript and entered data into the charts; KS organized the study, performed the searches, reviewed accepted papers, wrote sections of the manuscript, entered data into the charts and checked the validity of the data.

Conflict of interests: the authors declare had no potential conflict of interests.

Received for publication: 16 October 2011. Revision received: 9 February 2012.

Accepted for publication: 15 February 2012.

This work is licensed under a Creative Commons Attribution NonCommercial 3.0 License (CC BYNC 3.0).

(C) Copyright J. Borchard et al., 2012

Licensee PAGEPress, Italy

Alternative Medicine Studies 2012; 2:e6

doi:10.4081/ams.2012.e6

are related to defects in the action and regulation of NO and NOS.7 In pathological conditions, the isoforms of NOS are observed to be regulated differently. 18 High output of NO is injurious to a variety of tissues. ${ }^{14}$ For example, a possible mode of action for Alzheimer's disease may involve the inappropriate expression of NO by the apoE4 genotype. ${ }^{19,20}$ In addition, the inflammatory processes so commonly associated with obesity are associated with higher levels of NO.21,22 In diabetes, eNOS and nNOS are down-regulated, while iNOS is up-regulated.18 In aging, neuropathologies, and parasitemia, induction of iNOS, are observed. ${ }^{6}$ Deficiencies in the production of NO inhibit adhesion molecules and cytokine expression and diminish leukocyte transmigration. ${ }^{23}$ Insufficient NO release in the gastric associated lymphoid tissue, a key immunological site accounting for over $60 \%$ of all lymphoid tissue in the body, has been shown to be problematic for mucosal blood flow, gastrointestinal motility, mucus formation and bacteriostasis. ${ }^{24}$ Thus, the NO pathways are involved in many pathological processes.

Even though they are structurally similar, NOS isoforms differ in their dependence on $\mathrm{Ca}^{++} .25$ The constitutive isoforms in the brain and vasculature are regulated by calcium and calmodulin while the inducible iNOS, found in 
macrophages, is calcium independent.7 Thus, transcriptional and post-transcriptional regulation of these various isoforms is distinct rendering therapeutic intervention specific to iNOS, eNOS or nNOS. 18,26,27 This heterogeneity provides the potential for specific therapeutic targets in the modulation of NO expression; a goal of pharmaceutical research due to the panoply of diseases with which NO is associated. For example, corticoids inhibit the induction of iNOS while proinflammatory cytokines may induce iNOS. ${ }^{7}$

Previous studies have shown dietary variables to have an impact on NO expression. ${ }^{28-34}$ It is sensible, therefore, to consider the effect of plants in both a dietary and a medicinal scenario. Medicinal plants have been shown to influence a number of fundamental cellular processes and more research is being carried out into the effects of medicinal plants on NO. For example, Wang and Mazza ${ }^{35}$ demonstrated that the anti-inflammatory effects of specific anthocyanin and proanthocyanin rich plants may be due in part to the inhibition of NO production. A review of the primary literature suggests that many of the effects of herbal remedies involve up- or down-regulation of such messengers as NO, cytokines and adhesion molecules. ${ }^{36-39}$ This review of the primary literature demonstrates the effects of plant-based medicines on the expression of NO. Historically, the therapeutic use of medicinal plants included an array of diverse constituents or groups of constituents due to the phytochemical matrix of plant-based medicines. ${ }^{40}$ As Islam and Carter suggest, ${ }^{41}$ research into isolated constituents to reveal the modes of activity of herbal medicines loses sight of the principles of phytotherapy. Moreover, clinicians using medicinal plants in their practice generally use phytotherapeutic remedies that contain multiple constituents. Therefore, in order to maintain relevance to modern phytotherapy, this review was limited to herbal medicines that are available in the market place or preparations that represent multi-component phytochemical mixtures representative of a plant-based medicine approach.

\section{Materials and Methods}

\section{Search strategy}

The primary literature was searched in Pubmed, Web of Science, BIOSIS, and SciFinder Scholar. Titles were screened for all hits to the terms herbs and nitric oxide, medicinal plants and nitric oxide, Chinese medicine and nitric oxide, and Ayurveda and nitric oxide. The search only included English language papers.

\section{Criteria for inclusion}

The following inclusion criteria were adopted: i) Investigations on whole herbs or plant parts (e.g. seed, leaf, root, stem, flower or entire plant) or standardized extracts. Research on isolated constituents or herbal formulations were rejected. Fungi, although technically not plants, were included as they are commonly used in phytotherapy. ii) Model types were considered. In vitro, ex vivo, in vivo, animal and human models were accepted. iii) Two out of three of the following criteria were required to be transparent in the investigation: method of preparation of the botanical medicine, concentration of the plant preparation, or dose/exposure time. iv) Only studies demonstrating activity with regard to nitric oxide that showed a statistically significant result $(\mathrm{P}<0.05)$ were included.

\section{Results}

Out of 451 papers reviewed, only 44 papers met the established selection criteria. Data collected as a result of searches are shown in Tables 1-6.42-84 The majority of the research used in vitro models, but in vivo animal models were also utilized. Data in Tables 1-6 list the Genus species of the plants researched, followed by the plant parts used, methods of preparation, concentration/dose, duration of exposure, model utilized, nitric oxide pathway affected and references. Tables 1 and 2 show ex vivo results. Tables 3-6 list the in vitro results utilizing cell culture categorized by solvents used for the medicinal plant extractions (aqueous, ethanolic, and other extractions). The tables are divided into columns denoting the medicinal plant species, type of preparation/extraction (aqueous, ethanolic, powder etc.), concentration/dosage used, duration of exposure, the cell type, inducing agent and model (in vivo, ex vivo or in vitro). If one or more of these variables differed in an investigator's series of experiments (e.g. plant part, cell model or dose) a separate listing for each experimental condition is listed.

The most common model employed for assaying NO activity was based on the Greiss assay that uses sulfanilamide and N-1napthylethylenediamine to monitor the output of nitrite, a stable by product of NO production. The terms increase or decrease were used for these models. Investigations measuring enzyme concentration of NOS isoforms utilized Western blots (showing direct upregulation of NOS protein) or PCR was utilized to show the direct upregulation of NOS genes. The terms induction or inhibition were used for these models. The term stimulation was used to denote measures of increased NOS activity.
A large volume of research did not meet the inclusion criteria. Much of the rejected research was based on isolated constituents and offered little relevance for clinical phytotherapy. $85-87$ Research of semi-purified compounds like curcumin (a mixture of curcuminoids) or bromelain (a mixture of proteolytic enzymes) or isolates such as indole-3-carbinol were included only if they were readily available in commerce and/or frequently used by phytotherapists. One particular paper reporting a series of investigations that screened 83 plant extracts was included in this review. 75 However, due to the high dosage utilized in the screening process $(80 \mu \mathrm{g} / \mathrm{mL})$, only the six plant extracts that demonstrated dose dependent responses at the lowest dose that achieved over $40 \%$ inhibition of NO expression were included from this series of investigations. ${ }^{75}$

The majority of the available studies located on NO and medicinal plants generated data based on in vitro work. Of these, only 15 studies had concentrations of extracts that were at or below $10 \mu \mathrm{g} / \mathrm{mL}$. These included Crataegus pinnatifida, Ixeris dentate, Chasalia chartacea, Hedyotis verticillata, Lasianthus oblongus, Leea indica, Litsea cubeba, Spermacoce articularis, Thymus pulegioides, Brassica spp. (as the isolate indole-3-carbinol), Cocos nucifera, Echinacea angustifolia (combined with $E$. purpurea), Echinacea purpurea, Kalopanax pictus and Phellinus linteus. With rare exceptions, most in vitro models utilized macrophages and thus studied iNOS activity.

The significant findings of this literature review are that there are a multitude of medicinal plants that modulate the NO/NOS system. These effects are highlighted in Tables 1-6. Some of the most frequently used medicinal plants appear to interface with the NOS system. For example, Centella asiatica and Echinacea purpurea, both common medicinal plants, show activity on immune related NO release. However, $C$. asiatica was found to be an inhibitor of iNOS, while $E$. purpurea demonstrated increases in NO release in $e x$ vivo models. In an in vitro murine macrophage model $E$. purpurea was found to both increase and decrease iNOS activity as assessed by NO concentrations. Ginkgo biloba has also demonstrated decreases in iNOS activity and, as a result, in NO release in human macrophages. Two plants from the Ayurvedic system, Rubia cordifolia and Tinospora cordifolia, have both been found to inhibit iNOS activity and NO release in ex vivo models. Multiple other plants have also been found to be active in the reviewed studies as shown in Tables 1-6.

\section{Discussion}

The limitations in this collection of data are 
due to the use of in vitro and animal models in the bulk of the reviewed investigations. Replicating physiologically relevant models of human physiology are difficult with in vitro methods. Cells that survive, divide and then are utilized by in vitro experimental models are often poorly representative of cellular conditions in vivo, especially with regard to gene expression and enzyme levels. ${ }^{88}$ In addition, in vitro models fail to account for the digestive and metabolic processing of the multiple compounds present within a plant extract. In vitro models are also often poor representations of physiologically relevant serum concentrations. Moreover, the increased oxygen exposure in cell-culture conditions leads to more reactive oxygen species (ROS) generation and may impair cellular antioxidant defences. ${ }^{41}$ In considering in vitro research involving NOS and NO that are dependent on redox reactions, increased ROS generation due to cell culture conditions may have a dramatic impact on the results of these assays.

Animal models also may misrepresent human physiology. Artificially generated pathology, confounding variables, differences in anatomy and biochemical pathways all call into question the validity of data gathered from animal models. Accordingly, caution must be used when extrapolating data from in vitro and in vivo animal models. While in vitro and animal research models provide less than strong evidence, traditional use of medicinal plants has been shown to offer leads to biochemical and physiological effects of traditional remedies. For example, of 6,350 proven antimicrobial plant species, around $63 \%$ have ethnomedical documentation as antimicrobials. ${ }^{89}$ Additionally, $75 \%$ of new drugs made from nat-

Table 1. Medicinal plants demonstrating nitric oxide activity in ex vivo models.

\begin{tabular}{|c|c|c|c|c|c|c|c|c|c|}
\hline Genus species & $\begin{array}{l}\text { Plant } \\
\text { part }\end{array}$ & $\begin{array}{l}\text { Preparation } \\
\text { used }\end{array}$ & Dose & $\begin{array}{l}\text { Exposure } \\
\text { time }\end{array}$ & $\begin{array}{l}\text { Cell } \\
\text { type }\end{array}$ & Induced? & $\begin{array}{l}\text { System } \\
\text { affected }\end{array}$ & $\begin{array}{l}\text { Direction } \\
\text { of effect }\end{array}$ & Ref: \\
\hline Centella asiatica & $\begin{array}{l}\text { Herba and } \\
\text { radix }\end{array}$ & $\begin{array}{l}\text { Freeze-dried } \\
\text { aqueous } \\
\text { extract }\end{array}$ & $0.10 \mathrm{~g} / \mathrm{kg}$ & $24 \mathrm{~h}$ & $\begin{array}{l}\text { Murine gastric } \\
\text { tissue }\end{array}$ & $\begin{array}{l}\text { None } \\
\text { homogenat }\end{array}$ & & Inhibition & [42] \\
\hline Centella asiatica & $\begin{array}{l}\text { Herba and } \\
\text { radix }\end{array}$ & $\begin{array}{l}\text { Freeze-dried } \\
\text { aqueous } \\
\text { extract }\end{array}$ & $0.10 \mathrm{~g} / \mathrm{kg}$ & $24 \mathrm{~h}$ & $\begin{array}{l}\text { Murine gastric tissue } \\
\text { homogenate }\end{array}$ & None & NO & Decrease & [42] \\
\hline Dichroa febrifuga & Radix & $\begin{array}{l}\text { Aqueous } \\
\text { decoction }\end{array}$ & $\begin{array}{l}100 \mathrm{mg} / \mathrm{kg} \\
\text { Not specified }\end{array}$ & $20 \mathrm{~h}$ & Murine serum & LPS & iNOS & Inhibition & [43] \\
\hline Echinacea purpurea & $\begin{array}{l}\text { Herba and } \\
\text { radix }\end{array}$ & $\begin{array}{l}\text { Extract enriched } \\
\text { in *cichoric acid, } \\
\text { \#polysaccharides } \\
\text { **alkylamides }\end{array}$ & $\begin{array}{l}* 120 \mathrm{~g} / \mathrm{kg} / \mathrm{d} \\
\# 3000 \mathrm{~g} / \mathrm{kg} / \mathrm{d} \\
* * 12 \mathrm{~g} / \mathrm{kg} / \mathrm{d}\end{array}$ & 4 days & $\begin{array}{l}\text { Murine } \\
\text { alveolar macrophage }\end{array}$ & LPS & NO & Increase & [44] \\
\hline Emblica officinalis & Fructus & $\begin{array}{l}\text { Aqueous } \\
\text { extract }\end{array}$ & $25 \mathrm{mg} / \mathrm{kg}$ & 1020 & $\begin{array}{l}\text { Murine peritoneal } \\
\text { macrophage }\end{array}$ & $\mathrm{TG}$ & NO & Inhibition & [45] \\
\hline Eucommia ulmoides & Folia & $\begin{array}{l}\text { Aqueous } \\
\text { extract }\end{array}$ & $400 \mathrm{~g} / \mathrm{mL}$ & & $\begin{array}{l}\text { Murine } \\
\text { thoracic artery }\end{array}$ & L-NAME & eNOS & Stimulation & [46] \\
\hline Eucommia ulmoides & Cortex & $\begin{array}{l}\text { Aqueous } \\
\text { extract }\end{array}$ & $200 \mathrm{~g} / \mathrm{mL}$ & 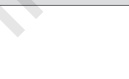 & $\begin{array}{l}\text { Murine } \\
\text { thoracic artery }\end{array}$ & L-NAME & eNOS & Stimulation & [46] \\
\hline Eucommia ulmoides & $\begin{array}{l}\text { Folia and } \\
\text { cortex }\end{array}$ & $\begin{array}{l}\text { Aqueous } \\
\text { extract }\end{array}$ & $200 \mathrm{~g} / \mathrm{mL}$ & & $\begin{array}{l}\text { Canine } \\
\text { thoracic artery }\end{array}$ & L-NAME & eNOS & Stimulation & [46] \\
\hline Evolvulus alsinoides & Herba & Aqueous & $25 \mathrm{mg} / \mathrm{kg}$ & $10 \mathrm{~d}$ & $\begin{array}{l}\text { Murine peritoneal } \\
\text { Macrophage }\end{array}$ & $\mathrm{TG}$ & NO & Decreased & [45] \\
\hline
\end{tabular}

Decrease/Increase, levels; Induction/Inhibition, enzyme models (NOS); Stimulation, increased enzyme activity; TG, thioglycolate; L-NAME, L-N(G)-nitroarginine methyl ester hydrochloride; LPS, lipopolysaccharide.

Table 2. Medicinal plants demonstrating nitric oxide activity in ex vivo models.

\begin{tabular}{|c|c|c|c|c|c|c|c|c|c|}
\hline Fagonia cretica & Radix & $\begin{array}{l}\text { Not } \\
\text { specified }\end{array}$ & $2 \mathrm{mg} / \mathrm{mL}$ & $2 \mathrm{~h}$ & $\begin{array}{l}\text { Murine } \\
\text { hippocampus }\end{array}$ & $\begin{array}{l}\text { Oxygen-glucose } \\
\text { deprivation }\end{array}$ & $\begin{array}{l}\text { NO } \\
\text { nNOS }\end{array}$ & $\begin{array}{l}\text { Decrease } \\
\text { inhibition }\end{array}$ & {$[47]$} \\
\hline Mollugo verticillata & Herba & $\begin{array}{l}\text { Ethanol, } \\
\text { lyophilized }\end{array}$ & $500 \mathrm{mg} / \mathrm{g}$ & $7 \mathrm{~d}$ & $\begin{array}{l}\text { Murine } \\
\text { macrophage }\end{array}$ & $\mathrm{BCG} \mathrm{Ag}$ & NO & Inhibition & {$[48]$} \\
\hline Perilla frutescens & Folia & $\begin{array}{l}\text { Aqueous } \\
\text { extract }\end{array}$ & $50 \mathrm{mg} / \mathrm{kg} / \mathrm{d}$ & 34 wks & $\begin{array}{l}\text { Murine } \\
\text { Serum }\end{array}$ & None & NO & Increased & [49] \\
\hline Rubia cordifolia & Radix & $\begin{array}{l}\text { Not } \\
\text { specified }\end{array}$ & $2 \mathrm{mg} / \mathrm{mL}$ & $2 \mathrm{~h}$ & $\begin{array}{l}\text { Murine } \\
\text { hippocampus }\end{array}$ & $\begin{array}{l}\text { Oxygen-glucose } \\
\text { deprivation }\end{array}$ & $\begin{array}{l}\text { NO } \\
\text { nNOS }\end{array}$ & $\begin{array}{l}\text { Decrease } \\
\text { Inhibition }\end{array}$ & {$[45]$} \\
\hline Sida cordifolia & Folium & $\begin{array}{l}\text { Aqueous } \\
\text { fraction }\end{array}$ & $20 \mathrm{mg} / \mathrm{kg}$, iv & One-time dose & $\begin{array}{l}\text { Murine aorta/ } \\
\text { vena cava }\end{array}$ & None & eNOS & Stimulation & {$[50]$} \\
\hline Spirodela polyrhixa & Not specified & $\begin{array}{l}\text { Aqueous } \\
\text { extract }\end{array}$ & $1 \mathrm{mg} / \mathrm{mL}$ & $1 \mathrm{~h}$ & $\begin{array}{l}\text { Murine peritoneal } \\
\text { macrophage }\end{array}$ & LPS & NO & Inhibition & {$[51]$} \\
\hline Spirodela polyrhixa & Not specified & $\begin{array}{l}\text { Aqueous } \\
\text { extract }\end{array}$ & $1 \mathrm{mg} / \mathrm{mL}$ & $1 \mathrm{~h}$ & $\begin{array}{l}\text { Murine peritoneal } \\
\text { macrophage }\end{array}$ & LPS & NO & Inhibition & {$[51]$} \\
\hline Tinospora cordifolia & Radix & $\begin{array}{l}\text { Not } \\
\text { specified }\end{array}$ & $2 \mathrm{mg} / \mathrm{mL}$ & $2 \mathrm{~h}$ & $\begin{array}{l}\text { Murine } \\
\text { hippocampus }\end{array}$ & $\begin{array}{l}\text { Oxygen-glucose } \\
\text { deprivation }\end{array}$ & $\begin{array}{l}\text { NO } \\
\text { nNOS }\end{array}$ & $\begin{array}{l}\text { Decrease } \\
\text { Inhibition }\end{array}$ & {$[47]$} \\
\hline
\end{tabular}

BCG Ag, Bacille Calmette Guérin Antigen from Mycobacterium bovis; LPS, lipopolysaccharide. 
ural products were discovered by following leads from traditional use of medicinal plants. 90 Thus, the reviewed data, which demonstrates the effects of herbal extracts on NO activity and NOS expression, may offer meaningful insight into the physiological activity and potential therapeutic indications when put into the context of traditional use. Furthermore, given the broad spectrum activity via stimulation of cell-to-cell communication by NO and, in turn, the broad spectrum activity of phytomedicines which can be viewed as complex chemical remedies, it is likely that some of the organ and tissue effects of these remedies are due, at least in part, to modulation of NO expression.

In the past decade, NO has been recognized as a primary messenger molecule of paramount functional significance with broad spectrum activity. The activity of NO is not dependent primarily on NOS isoforms but rather on NO concentrations, leukocyte priming, and cellular context. ${ }^{23} \mathrm{NO}$ has been found to be a pleiotropic mediator of inflammation. ${ }^{91}$ In addition, dependent on concentration, NO is involved in protection against or induction of oxidative stress in many tissues. With this dual role in mind, Cooke ${ }^{92}$ suggests a yinyang effect of NO in physiological function. Overproduction of NO is of primary importance and is proinflammatory, inducing cellular damage via oxidative stress, characterizing atherosclerosis, as well as insulin resistance. Conversely, a reduction in production of NO may be involved in initiation and progression of atherosclerosis.23,92-94 The endothelial isoform of NOS, eNOS, is believed to play a role in limiting the acute phase of inflammation by inhibiting leukocyte activation and platelet aggregation, and by inducing vasodilatation. ${ }^{95}$

Achike and Kwan ${ }^{95}$ also recognize pleiotropic activity of $\mathrm{NO}$ as yin/yang suggesting that an imbalance in vascular function relates to the yin (vascular relaxation) and yang (vascular contraction) balance of the system. They suggest that hypertension is due to an excessive yang nature, while hypotension is considered excessive yin nature. Ou et al. ${ }^{96}$ suggest that herbs that show strong antioxidant activity were yin in nature after comparing the results of herbs known in traditional Chinese medicine as yin or yang that were evaluated by the oxygen radical absorbance capacity (ORAC) assay. Intriguingly, of the herbs suggested to be yin in nature, many are, in the proper clinical context, used to treat cardiac conditions, including hypertension which is commonly considered a yang condition. These include Astragalus membranaceous, Crataegus pinnatifida, Emblica officinalis, Eucommia ulmoides, Evolvulus alsinoides, Nigella sativa and Oldenlandia diffusa.

Cooke's ${ }^{92}$ suggestion of NO having an amphoteric effect relates to the activity of some of the reviewed medicinal plants that are believed to amphoterically regulate physiology. For example, extracts from Echinacea spp., once thought to be simple immune stimulants, have shown both immune enhancing and immune dampening effects. Echinacea extracts have demonstrated immune stimulatory activity in mice, ${ }^{97}$ cattle, ${ }^{98}$ and humans. ${ }^{99}$ The alkylamides of Echinacea spp. have also shown increases in the proinflammatory tumor necrosis factor alpha in macrophages (TNF- $\alpha$ ). 100 Conversely, recent studies demonstrate downregulation of the inflammatory cytokines by the alkylamides, including IL-1,101 IL-2,102 IL-12,101 TNF- $\alpha, 101,103$ as well as by an Echinacea extract (IL-1 $\beta$, IL-8, TNF- $\alpha$ ) consumed by adult humans. ${ }^{104}$ With regard to the

Table 3. Aqueous extracts of medicinal plants demonstrating nitric oxide activity, in vitro models.

\begin{tabular}{|c|c|c|c|c|c|c|c|c|c|}
\hline Genus species & $\begin{array}{l}\text { Plant } \\
\text { part }\end{array}$ & $\begin{array}{l}\text { Preparation } \\
\text { used }\end{array}$ & $\begin{array}{l}\text { Active } \\
\text { concentration }\end{array}$ & $\begin{array}{l}\text { Exposure } \\
\text { time }\end{array}$ & $\begin{array}{l}\text { Cell } \\
\text { type }\end{array}$ & Induced? & $\begin{array}{l}\text { System } \\
\text { affected }\end{array}$ & $\begin{array}{l}\text { Direction } \\
\text { of effect }\end{array}$ & Ref. \\
\hline Astragalus membranaceous & Radix & $\begin{array}{l}\text { Aqueous } \\
\text { extract }\end{array}$ & $\begin{array}{l}20 \mu \mathrm{g} / \mathrm{mL} \\
2000 \mu \mathrm{g} / \mathrm{mL}\end{array}$ & $24 \mathrm{~h}$ & $\begin{array}{l}\text { Murine } \\
\text { macrophage }\end{array}$ & LPS+ & $\begin{array}{l}\text { NO } \\
\text { iNOS }\end{array}$ & $\begin{array}{l}\text { Decrease } \\
\text { inhibition }\end{array}$ & [52] \\
\hline Centella asiatica & $\begin{array}{l}\text { Herba } \\
\text { and radix }\end{array}$ & $\begin{array}{l}\text { Aqueous } \\
\text { extract }\end{array}$ & $125 \mu \mathrm{g} / \mathrm{mL}$ & $24 \mathrm{~h}$ & $\begin{array}{l}\text { Murine } \\
\text { macrophage }\end{array}$ & $\begin{array}{l}\text { None } \\
\text { LPS + }\end{array}$ & $\begin{array}{l}\text { NO } \\
\text { NO }\end{array}$ & $\begin{array}{l}\text { Increase } \\
\text { Increase }\end{array}$ & [53] \\
\hline Crataegus pinnatifida & Fructus & $\begin{array}{l}\text { Aqueous } \\
\text { extract }\end{array}$ & $10 \mu \mathrm{g} / \mathrm{mL}$ & $\begin{array}{l}\text { Not } \\
\text { specified }\end{array}$ & $\begin{array}{l}\text { Murine } \\
\text { macrophage }\end{array}$ & SNP & NO & Decrease & [54] \\
\hline Dichroa febrifuga & Radix & $\begin{array}{l}\text { Aqueous } \\
\text { extract }\end{array}$ & $\begin{array}{l}83 \mu \mathrm{g} / \mathrm{mL} \\
250 \mu \mathrm{g} / \mathrm{mL} \\
150 \mu \mathrm{g} / \mathrm{mL} \\
250 \mu \mathrm{g} / \mathrm{mL}\end{array}$ & $22 \mathrm{~h}$ & $\begin{array}{l}\text { Murine } \\
\text { peritoneal } \\
\text { macrophage }\end{array}$ & $\begin{array}{l}\text { LPS } \\
\text { LPS + } \\
\text { IFN- } \gamma\end{array}$ & $\begin{array}{l}\text { NO } \\
\text { iNOS } \\
\text { NO } \\
\text { iNOS }\end{array}$ & $\begin{array}{l}\text { Decrease } \\
\text { inhibition } \\
\text { Decrease } \\
\text { inhibition }\end{array}$ & {$[43]$} \\
\hline Euonymus alatus & $\begin{array}{l}\text { Cortex } \\
\text { and cork }\end{array}$ & $\begin{array}{l}\text { Aqueous } \\
\text { extract }\end{array}$ & $\begin{array}{l}100 \mu \mathrm{g} / \mathrm{mL} \\
1000 \mu \mathrm{g} / \mathrm{mL}\end{array}$ & $\begin{array}{l}6 \mathrm{~h} \\
12 \mathrm{~h}\end{array}$ & $\begin{array}{l}\text { Mouse peritoneal } \\
\text { macrophage }\end{array}$ & $\begin{array}{l}\text { IFN- } \gamma \\
\text { iNOS }\end{array}$ & NO & $\begin{array}{l}\text { Increase } \\
\text { induced }\end{array}$ & [55] \\
\hline Ixeris dentata & $\begin{array}{l}\text { Not } \\
\text { specified }\end{array}$ & $\begin{array}{l}\text { Fresh plant } \\
\text { mash }\end{array}$ & $\begin{array}{l}1.0 \mu \mathrm{g} / \mathrm{mL} \\
100 \mu \mathrm{g} / \mathrm{mL}\end{array}$ & $\begin{array}{l}6 \mathrm{~h} \\
12 \mathrm{~h}\end{array}$ & $\begin{array}{l}\text { Mouse } \\
\text { peritoneal }\end{array}$ & rIFN- $\gamma$ & NO & Increase & {$[56]$} \\
\hline Kalopanax pictus & $\begin{array}{l}\text { Ramulus } \\
\text { cortex }\end{array}$ & $\begin{array}{l}\mathrm{H}_{2} \mathrm{O} \text { extraction } \\
\mathrm{KPR}-1 \\
\mathrm{~K}-1\end{array}$ & $\begin{array}{l}34.15 \mathrm{ug} / \mathrm{mL} \\
43.24 \mathrm{ug} / \mathrm{mL}\end{array}$ & $10 \mathrm{~min}$ & $\begin{array}{l}\text { Murine } \\
\text { macrophage }\end{array}$ & LPS & NO & Inhibition & {$[57]$} \\
\hline Lactuca indica & $\begin{array}{l}\text { Fresh } \\
\text { plant }\end{array}$ & $\begin{array}{l}\text { Hot water } \\
\text { extract }\end{array}$ & $50 \mu \mathrm{g} / \mathrm{mL}$ & $6 \mathrm{~h}$ & $\begin{array}{l}\text { Murine } \\
\text { macrophage }\end{array}$ & LPS & iNOS & Inhibition & [58] \\
\hline Lithospermum erythrorhizon & Radix & Aqueous 1:1 & $\begin{array}{l}100 \mu \mathrm{g} / \mathrm{mL} \\
1000 \mu \mathrm{g} / \mathrm{mL}\end{array}$ & $48 \mathrm{~h}$ & $\begin{array}{l}\text { Murine } \\
\text { macrophage }\end{array}$ & $\begin{array}{l}\text { rIFN- } \gamma+ \\
\text { LPS+ }\end{array}$ & $\begin{array}{l}\text { NO } \\
\text { iNOS }\end{array}$ & $\begin{array}{l}\text { Decreased } \\
\text { inhibition }\end{array}$ & [59] \\
\hline Nigella sativa & Semen & $\begin{array}{l}\text { Boiled aqueous } \\
\text { extract 1:3 }\end{array}$ & $50 \mu \mathrm{L}$ & $2 \mathrm{~h}$ & $\begin{array}{l}\text { Murine } \\
\text { peritoneal } \\
\text { macrophage }\end{array}$ & LPS & NO & Inhibition & {$[60]$} \\
\hline Oldenlandia diffusa & Folia & Decoction & $1000 \mu \mathrm{g} / \mathrm{mL}$ & $\begin{array}{l}6 \mathrm{~h} \\
12 \mathrm{~h}\end{array}$ & $\begin{array}{l}\text { Mouse peritoneal } \\
\text { macrophage }\end{array}$ & rIFN- $\gamma+$ & $\begin{array}{l}\text { NO } \\
\text { iNOS }\end{array}$ & $\begin{array}{l}\text { Increased } \\
\text { induction }\end{array}$ & {$[61]$} \\
\hline Pueraria thunbergiana & Flos & $\begin{array}{l}\text { Aqueous } \\
\text { extraction }\end{array}$ & $55.8 \mathrm{ug} / \mathrm{mL}$ & $10 \mathrm{~min}$ & $\begin{array}{l}\text { Murine } \\
\text { macrophage }\end{array}$ & LPS & NO & Decrease & [62] \\
\hline Rhus verniciflua & Lignum & $\begin{array}{l}\text { Aqueous } \\
\text { extraction }\end{array}$ & $22 \mathrm{ug} / \mathrm{mL}$ & $10 \mathrm{~min}$ & $\begin{array}{l}\text { Murine } \\
\text { macrophage }\end{array}$ & LPS & NO & Inhibition & [62] \\
\hline
\end{tabular}

KPR-1, aqueous extraction of Kalopanax pictus; K-1, aqueous extraction of Kalopanax pictus; LPS, lipopolysaccharide. 
effect of Echinacea extracts on NO, Goel et al.44 and Rininger et al. ${ }^{81}$ report an increase in the production of NO from macrophages. In contrast, Stevenson et al. revealed an inhibitory effect on NO production from macrophages. Both Rininger and Stevenson's in vitro models were in the range of physiologically relevant serum concentrations and used lipopolysaccharide as a macrophage primer. Nonetheless, they show opposing activity. This may be due to one extract undergoing simulated digestion while the other represented only the lipophilic fraction of $E$. purpurea radix. These studies demonstrate the folly of relying only on in vitro results for understanding pharmacology where the context of pathophysiological condition is difficult to replicate. This may also be an example of various constituents having opposing activities in medicinal plant extracts.

Another example of a medicinal plant that influences the NO pathways is turmeric (Curcuma longa) which has been used historically as both a food spice and medicine throughout India and southeast Asia. Traditional applications of the plant include treatment of inflammation, skin wounds and tumors.105 Clinical trials have investigated the efficacy of both turmeric extract and curcumin, an isolated mixture of the yellow/orange pigments known as curcuminoids that give turmeric its characteristic color. Curcumin is widely available on the market and used in irritable bowel syndrome, colorectal cancer, pancreatitis, osteoarthritis and peptic and gastric ulcers. ${ }^{106}$ Research has demonstrated the antiinflammatory, ${ }^{107}$ antioxidant, ${ }^{108}$ and anticarcinogenic ${ }^{109}$ activity of curcumin. These effects are suggested to involve multiple pathways and modes of activity, such as inhibition

Table 4. Alcohol extracts of medicinal plants demonstrating nitric oxide activity; in vitro models.

\begin{tabular}{|c|c|c|c|c|c|c|c|c|c|}
\hline Genus species & $\begin{array}{l}\text { Plant } \\
\text { part }\end{array}$ & $\begin{array}{l}\text { Preparation } \\
\text { used }\end{array}$ & $\begin{array}{l}\text { Active } \\
\text { concentration }\end{array}$ & $\begin{array}{l}\text { Exposure } \\
\text { time }\end{array}$ & $\begin{array}{l}\text { Cell } \\
\text { type }\end{array}$ & Induced? & $\begin{array}{l}\text { NOS } \\
\text { affected }\end{array}$ & $\begin{array}{l}\text { Direction } \\
\text { of effect }\end{array}$ & Ref. \\
\hline Acorus calamus & Rhizome & $\begin{array}{l}\text { Ethanol } \\
\text { Extract }\end{array}$ & $100 \mu \mathrm{g} / \mathrm{mL}$ & $24 \mathrm{~h}$ & $\begin{array}{l}\text { Murine } \\
\text { macrophage }\end{array}$ & $\begin{array}{l}\text { LPS } \\
\text { None }\end{array}$ & $\begin{array}{l}\text { NO } \\
\text { NO }\end{array}$ & $\begin{array}{l}\text { Decrease } \\
\text { Decrease }\end{array}$ & [63] \\
\hline Bidens pilosa & Herba & $\begin{array}{l}\text { Ethanol } \\
\text { Extract }\end{array}$ & $100 \mathrm{ug} / \mathrm{mL}$ & $24 \mathrm{~h}$ & $\begin{array}{l}\text { Murine } \\
\text { macrophage }\end{array}$ & LPS & NO & Inhibition & [64] \\
\hline Catalpa ovata & $\begin{array}{l}\text { Caulis } \\
\text { cortex }\end{array}$ & $\begin{array}{l}\text { Methanol } \\
\text { Extract }\end{array}$ & $\begin{array}{l}100 \mathrm{ug} / \mathrm{mL} \\
100 \mathrm{ug} / \mathrm{mL}\end{array}$ & $\begin{array}{l}24 \mathrm{~h} \\
4 \mathrm{~h}\end{array}$ & $\begin{array}{l}\text { Murine } \\
\text { macrophage }\end{array}$ & LPS & $\begin{array}{l}\text { NO } \\
\text { iNOS }\end{array}$ & $\begin{array}{l}\text { Decrease } \\
\text { inhibition }\end{array}$ & [65] \\
\hline Centella asiatica & $\begin{array}{l}\text { Herba and } \\
\text { radix }\end{array}$ & $\begin{array}{l}\text { Ethanol } \\
\text { extract }\end{array}$ & $\begin{array}{l}500 \mu \mathrm{g} / \mathrm{mL} \\
100 \mu \mathrm{g} / \mathrm{mL}\end{array}$ & $24 \mathrm{~h}$ & $\begin{array}{l}\text { Murine LPS } \\
\text { macrophage }\end{array}$ & NO & iNOS & $\begin{array}{l}\text { Decrease } \\
\text { inhibition }\end{array}$ & [53] \\
\hline Chasalia chartacea & $\begin{array}{l}\text { Herba and } \\
\text { radix }\end{array}$ & $\begin{array}{l}\text { Methanol } \\
\text { extract }\end{array}$ & $2.5 \mu \mathrm{g} / \mathrm{mL}$ & $24 \mathrm{~h}$ & $\begin{array}{l}\text { Murine } \\
\text { macrophage }\end{array}$ & IFN $-\gamma+$ LPS & NO & Decrease & {$[66]$} \\
\hline Cupania vernalis & Folium & $\begin{array}{l}\text { Ethanol } \\
\text { extract }\end{array}$ & $50 \mu \mathrm{g} / \mathrm{mL}$ & $48 \mathrm{~h}$ & $\begin{array}{l}\text { Murine } \\
\text { Macrophage }\end{array}$ & $L P S+I F N-\gamma$ & iNOS & Inhibition & [67] \\
\hline Ganoderma lucidum & Fruiting body & $\begin{array}{l}\text { Ethanol } \\
\text { extract }\end{array}$ & $100 \mathrm{ug} / \mathrm{mL}$ & $24 \mathrm{~h}$ & $\begin{array}{l}\text { Murine } \\
\text { Macrophage }\end{array}$ & $\mathrm{LPS}+\mathrm{IFN}-\gamma$ & NO & Decrease & [68] \\
\hline Hedyotis verticillata & $\begin{array}{l}\text { Herba and } \\
\text { radix }\end{array}$ & $\begin{array}{l}\text { Methanol } \\
\text { extract }\end{array}$ & $2.5 \mu \mathrm{g} / \mathrm{mL}$ & $24 \mathrm{~h}$ & $\begin{array}{l}\text { Murine } \\
\text { macrophage }\end{array}$ & IFN- $\gamma+$ LPS & NO & Decrease & {$[66]$} \\
\hline Lasianthus oblongus & $\begin{array}{l}\text { Herba and } \\
\text { radix }\end{array}$ & $\begin{array}{l}\text { Methanol } \\
\text { extract }\end{array}$ & $2.5 \mu \mathrm{g} / \mathrm{mL}$ & $24 \mathrm{~h}$ & $\begin{array}{l}\text { Murine } \\
\text { macrophage }\end{array}$ & IFN- $\gamma+$ LPS & NO & Decrease & {$[66]$} \\
\hline Leea indica & $\begin{array}{l}\text { Herba and } \\
\text { radix }\end{array}$ & $\begin{array}{l}\text { Methanol } \\
\text { extract }\end{array}$ & $2.5 \mu \mathrm{g} / \mathrm{mL}$ & $24 \mathrm{~h}$ & $\begin{array}{l}\text { Murine } \\
\text { macrophage }\end{array}$ & IFN- $\gamma+$ LPS & NO & Decrease & {$[66]$} \\
\hline Litsea cubeba & Cortex & $\begin{array}{l}\text { Methanol } \\
\text { extract }\end{array}$ & $10 \mathrm{ug} / \mathrm{mL}$ & $24 \mathrm{~h}$ & $\begin{array}{l}\text { Murine } \\
\text { macrophage }\end{array}$ & LPS & iNOS & Inhibition & [69] \\
\hline Mollugo verticillata & Herba & $\begin{array}{l}\text { Ethanol } \\
\text { extract }\end{array}$ & $25 \mu \mathrm{g} / \mathrm{mL}$ & $48 \mathrm{~h}$ & $\begin{array}{l}\text { Murine } \\
\text { macrophage }\end{array}$ & $\begin{array}{l}\text { None } \\
\text { BCG Ag }\end{array}$ & NO & $\begin{array}{l}\text { Increases } \\
\text { decreases }\end{array}$ & [48] \\
\hline Propolis & - & $\begin{array}{l}\text { Warm ethanol } \\
\text { extract }\end{array}$ & $30 \mu \mathrm{g} / \mathrm{mL}$ & $24 \mathrm{~h}$ & $\begin{array}{l}\text { Murine } \\
\text { macrophage }\end{array}$ & LPS & $\begin{array}{l}\text { NO } \\
\text { iNOS }\end{array}$ & $\begin{array}{l}\text { Decrease } \\
\text { inhibition }\end{array}$ & [70] \\
\hline Rhinacanthus nasutus & $\begin{array}{l}\text { Caulis and } \\
\text { folia }\end{array}$ & $\begin{array}{l}\text { Ethanol } \\
\text { extract }\end{array}$ & $250 \mu \mathrm{g} / \mathrm{mL}$ & $24 \mathrm{~h}$ & $\begin{array}{l}\text { Murine } \\
\text { macrophage }\end{array}$ & LPS & NO & Increase & [53] \\
\hline Serjania lethalis & $\begin{array}{l}\text { Ramulus } \\
\text { lignum }\end{array}$ & $\begin{array}{l}\text { Ethanol } \\
\text { extract }\end{array}$ & $50 \mu \mathrm{g} / \mathrm{mL}$ & $48 \mathrm{~h}$ & $\begin{array}{l}\text { Murine } \\
\text { Macrophage }\end{array}$ & $\mathrm{LPS}+\mathrm{IFN}-\gamma$ & iNOS & Inhibition & {$[67]$} \\
\hline Spermacoce articularis & $\begin{array}{l}\text { Herba and } \\
\text { radix }\end{array}$ & $\begin{array}{l}\text { Methanol } \\
\text { extract }\end{array}$ & $2.5 \mu \mathrm{g} / \mathrm{mL}$ & $24 \mathrm{~h}$ & $\begin{array}{l}\text { Murine } \\
\text { macrophage }\end{array}$ & IFN- $\gamma+$ LPS & NO & Decrease & {$[66]$} \\
\hline Taraxacum officinale & Flos & $\begin{array}{l}\text { Ethanol } \\
\text { extraction }\end{array}$ & $130 \mathrm{ug} / \mathrm{mL}$ & $24 \mathrm{~h}$ & $\begin{array}{l}\text { Murine } \\
\text { macrophage }\end{array}$ & LPS & NO & Inhibition & [71] \\
\hline Taxus yunnanensis & Lignum & $\begin{array}{l}\mathrm{H}_{2} \mathrm{O} / \text { methanol } \\
\text { extract }\end{array}$ & $40.3 \mathrm{ug} / \mathrm{mL}$ & $24 \mathrm{~h}$ & $\begin{array}{l}\text { Murine } \\
\text { macrophage }\end{array}$ & LPS & iNOS & Inhibition & [72] \\
\hline Taxus yunnanensis & Lignum & $\begin{array}{l}\text { Methanol } \\
\text { extract }\end{array}$ & $34.2 \mathrm{ug} / \mathrm{mL}$ & $24 \mathrm{~h}$ & $\begin{array}{l}\text { Murine } \\
\text { macrophage }\end{array}$ & LPS & iNOS & Inhibition & [72] \\
\hline Thymus pulegioides & Folium & $\begin{array}{l}\text { Hot ethanol } \\
\text { extract }\end{array}$ & $1 \mathrm{uM} \mathrm{GAE}$ & $16 \mathrm{~h}$ & $\begin{array}{l}\text { Porcine aortic } \\
\text { endothelial cells }\end{array}$ & A23187 & eNOS & Stimulation & [73] \\
\hline Ulmus davidiana & $\begin{array}{l}\text { Ramulus } \\
\text { cortex }\end{array}$ & $\begin{array}{l}\text { Hot methanol } \\
\text { extract }\end{array}$ & $100 \mathrm{ug} / \mathrm{mL}$ & $48 \mathrm{~h}$ & $\begin{array}{l}\text { Murine } \\
\text { macrophage }\end{array}$ & $\mathrm{LPS}+\mathrm{IFN}-\gamma$ & NO & Decrease & [74] \\
\hline
\end{tabular}

BCG Ag, Bacille Calmette Guérin Antigen from Mycobacterium bovis; GAE, Gallic Acid Equivalents; LPS, lipopolysaccharide. 
Table 5. Other extracts of medicinal plants demonstrating nitric oxide activity; in vitro models.

\begin{tabular}{|c|c|c|c|c|c|c|c|c|c|}
\hline Genus species & $\begin{array}{l}\text { Plant } \\
\text { part }\end{array}$ & $\begin{array}{l}\text { Preparation } \\
\text { used }\end{array}$ & $\begin{array}{l}\text { Active } \\
\text { concentration }\end{array}$ & $\begin{array}{l}\text { Exposure } \\
\text { time }\end{array}$ & $\begin{array}{l}\text { Cell } \\
\text { type }\end{array}$ & Induced? & $\begin{array}{l}\text { NOS } \\
\text { affected }\end{array}$ & $\begin{array}{l}\text { Direction } \\
\text { of effect }\end{array}$ & Ref. \\
\hline Abies koreana & $\begin{array}{l}\text { Ramulus } \\
\text { cortex }\end{array}$ & $\begin{array}{l}\mathrm{MeOH}, \\
\text { ethyl ether }\end{array}$ & $40 \mathrm{ug} / \mathrm{mL}$ & $20 \mathrm{~h}$ & $\begin{array}{l}\text { Murine } \\
\text { macrophage }\end{array}$ & LPS & iNOS & Inhibition & {$[75]$} \\
\hline Artemisia iwayomogi & $\begin{array}{l}\text { Ramulus } \\
\text { cortex }\end{array}$ & $\begin{array}{l}\mathrm{MeOH} \text {, } \\
\text { ethyl ether }\end{array}$ & $40 \mathrm{ug} / \mathrm{mL}$ & $20 \mathrm{~h}$ & $\begin{array}{l}\text { Murine } \\
\text { macrophage }\end{array}$ & LPS & iNOS & Inhibition & {$[75]$} \\
\hline Ananus comosus & Herba & Bromelain & $15 \mathrm{ug} / \mathrm{mL}$ & $24 \mathrm{~h}$ & $\begin{array}{l}\text { Murine } \\
\text { macrophage }\end{array}$ & IFN- $\gamma$ & NO & Increase & {$[76]$} \\
\hline Ananus comosus & Herba & Bromelain & $50 \mathrm{ug} / \mathrm{mL}$ & $24 \mathrm{~h}$ & $\begin{array}{l}\text { Murine bone } \\
\text { marrow } \\
\text { macrophage }\end{array}$ & $\begin{array}{l}\text { None } \\
\text { IFN-y }\end{array}$ & $\begin{array}{l}\text { NO } \\
\text { NO }\end{array}$ & $\begin{array}{l}\text { Increase } \\
\text { Increase }\end{array}$ & {$[76]$} \\
\hline Bidens pilosa & Herba & Ethyl acetate & $36.2 \mathrm{ug} / \mathrm{mL}$ & $24 \mathrm{~h}$ & $\begin{array}{l}\text { Murine } \\
\text { macrophage }\end{array}$ & LPS & NO & Inhibition & {$[64]$} \\
\hline Brassica spp. & Isolate & Indole-3-carbinol & $0.001 \mathrm{uM}$ & $24 \mathrm{~h}$ & $\begin{array}{l}\text { Murine } \\
\text { macrophage }\end{array}$ & $\begin{array}{l}\mathrm{LPS}+ \\
\text { IFN- } \gamma\end{array}$ & $\begin{array}{l}\text { NO } \\
\text { iNOS }\end{array}$ & $\begin{array}{l}\text { Decrease } \\
\text { Inhibition }\end{array}$ & {$[77]$} \\
\hline Broussonetia kazinoki & $\begin{array}{l}\text { Ramulus cortex } \\
\text { ethyl ether }\end{array}$ & $\mathrm{MeOH}$ & $20 \mathrm{ug} / \mathrm{mL}$ & $20 \mathrm{~h}$ & $\begin{array}{l}\text { Murine } \\
\text { macrophage }\end{array}$ & LPS & iNOS & Inhibition & {$[75]$} \\
\hline Casearia Sylvestris & $\begin{array}{l}\text { Ramulus } \\
\text { cortex }\end{array}$ & Hexane & $50 \mu \mathrm{g} / \mathrm{mL}$ & $48 \mathrm{~h}$ & $\begin{array}{l}\text { Murine } \\
\text { macrophage }\end{array}$ & $\begin{array}{l}\text { LPS } \\
\text { IFN-ץ }\end{array}$ & iNOS & Inhibition & {$[67]$} \\
\hline Chicorium intybus & Radix & Inulin isolate & $\begin{array}{l}10 \mathrm{ug} / \mathrm{mL} \\
1000 \mathrm{ug} / \mathrm{mL}\end{array}$ & $\begin{array}{l}24 \mathrm{~h} \\
24 \mathrm{~h}\end{array}$ & $\begin{array}{l}\text { Murine } \\
\text { macrophage }\end{array}$ & $\begin{array}{l}\text { LPS } \\
\text { IFN- } \gamma\end{array}$ & $\begin{array}{l}\text { NO } \\
\text { iNOS }\end{array}$ & $\begin{array}{l}\text { Increase } \\
\text { Induction }\end{array}$ & {$[78]$} \\
\hline Cocos nucifera & Husk fiber & Ethyl acetate & $10 \mu \mathrm{g} / \mathrm{mL}$ & $1.9 \mathrm{~h}$ & $\begin{array}{l}\text { Murine } \\
\text { peritoneal } \\
\text { macrophage }\end{array}$ & $\begin{array}{l}\text { Leishmania } \\
\text { infection }\end{array}$ & NO & Increased & {$[79]$} \\
\hline Curcuma zedoaria & Rhizome & Curcumin & $20 \mathrm{uM}$ & $18 \mathrm{~h}$ & $\begin{array}{l}\text { Murine } \\
\text { macrophage }\end{array}$ & LPS & iNOS & Inhibition & {$[80]$} \\
\hline
\end{tabular}

Table 6. Other extracts of medicinal plants demonstrating nitric oxide activity; in vitro models.

\begin{tabular}{|c|c|c|c|c|c|c|c|c|c|}
\hline Genus species & $\begin{array}{l}\text { Plant } \\
\text { part }\end{array}$ & $\begin{array}{l}\text { Preparation } \\
\text { used }\end{array}$ & $\begin{array}{l}\text { Active } \\
\text { concentratio }\end{array}$ & $\begin{array}{l}\text { Exposure } \\
\text { I time }\end{array}$ & $\begin{array}{l}\text { Cell } \\
\text { type }\end{array}$ & Induced? & $\begin{array}{l}\text { NOS } \\
\text { affected }\end{array}$ & $\begin{array}{l}\text { Direction } \\
\text { of effect }\end{array}$ & Ref. \\
\hline Echinaceapurpurea & $\begin{array}{l}\text { Herba and } \\
\text { radix }\end{array}$ & $\begin{array}{l}\text { Simulated } \\
\text { digestion }\end{array}$ & $5 \mathrm{ug} / \mathrm{mL}$ & $24 \mathrm{~h}$ & $\begin{array}{l}\text { Murine } \\
\text { macrophage }\end{array}$ & LPS & NO & Increase & [81] \\
\hline $\begin{array}{l}\text { E.purpurea \& } \\
\text { E. angustifolia }\end{array}$ & Radix & $\begin{array}{l}\text { Lipophilic } \\
\text { extract }\end{array}$ & $2.0 \mathrm{ug} / \mathrm{mL}$ & $21 \mathrm{~h}$ & $\begin{array}{l}\text { Murine } \\
\text { macrophage }\end{array}$ & LPS & NO & Decrease & [82] \\
\hline Ginkgo biloba & Folia & Standardized & $\begin{array}{l}100 \mu \mathrm{\mu g} / \mathrm{mL} \\
100 \mathrm{ug} / \mathrm{mL}\end{array}$ & $4 \mathrm{~h}$ & $\begin{array}{l}\text { Human } \\
\text { macrophage }\end{array}$ & PMA & $\begin{array}{l}\text { NO } \\
\text { iNOS }\end{array}$ & $\begin{array}{l}\text { Decrease } \\
\text { Inhibition }\end{array}$ & [83] \\
\hline Idesia polycarpa & $\begin{array}{l}\text { Ramulus } \\
\text { cortex }\end{array}$ & $\begin{array}{l}\mathrm{MeOH} \text {, } \\
\text { ethyl ether }\end{array}$ & $40 \mathrm{ug} / \mathrm{mL}$ & $20 \mathrm{~h}$ & $\begin{array}{l}\text { Murine } \\
\text { macrophage }\end{array}$ & LPS & iNOS & Inhibition & [75] \\
\hline Machilus thunbergii & $\begin{array}{l}\text { Ramulus } \\
\text { cortex }\end{array}$ & $\begin{array}{l}\mathrm{MeOH} \text {, } \\
\text { ethyl ether }\end{array}$ & $40 \mathrm{ug} / \mathrm{mL}$ & $20 \mathrm{~h}$ & $\begin{array}{l}\text { Murine } \\
\text { macrophage }\end{array}$ & LPS & iNOS & Inhibition & [75] \\
\hline Morus bombycis & $\begin{array}{l}\text { Ramulus } \\
\text { cortex }\end{array}$ & $\begin{array}{l}\text { MeOH, } \\
\text { ethyl ether }\end{array}$ & $40 \mathrm{ug} / \mathrm{mL}$ & $20 \mathrm{~h}$ & $\begin{array}{l}\text { Murine } \\
\text { macrophage }\end{array}$ & LPS & iNOS & Inhibition & [75] \\
\hline Kalopanax pictus & $\begin{array}{l}\text { Ramulus } \\
\text { cortex }\end{array}$ & $\begin{array}{l}\text { Chloroform, } \\
\text { ethyl acetate }\end{array}$ & $9.5 \mathrm{ug} / \mathrm{mL}$ & $10 \mathrm{~min}$ & $\begin{array}{l}\text { Murine } \\
\text { macrophage }\end{array}$ & LPS & NO & Inhibition & [56] \\
\hline Phellinus linteus & $\begin{array}{l}\text { Fruiting } \\
\text { body }\end{array}$ & $\begin{array}{l}\text { Polysaccharide } \\
\text { precipitate }\end{array}$ & $10 \mu \mathrm{g} / \mathrm{mL}$ & $48 \mathrm{~h}$ & $\begin{array}{l}\text { Murine } \\
\text { peritoneal } \\
\text { macrophage }\end{array}$ & None & NO & Increase & [84] \\
\hline Populus davidiana & Ramulus cortex & $\begin{array}{l}\mathrm{MeOH}, \\
\text { ethyl ether }\end{array}$ & $20 \mathrm{ug} / \mathrm{mL}$ & $20 \mathrm{~h}$ & $\begin{array}{l}\text { Murine } \\
\text { macrophage }\end{array}$ & LPS & iNOS & Inhibition & [75] \\
\hline Populus maximowiczii & Ramulus cortex & $\begin{array}{l}\mathrm{MeOH} \text {, } \\
\text { ethyl ether }\end{array}$ & $20 \mathrm{ug} / \mathrm{mL}$ & $20 \mathrm{~h}$ & $\begin{array}{l}\text { Murine } \\
\text { macrophage }\end{array}$ & LPS & iNOS & Inhibition & [75] \\
\hline Pueraria thunbergiana & Flos & $\begin{array}{l}\text { Chloroform, } \\
\text { ethyl acetate }\end{array}$ & $26.1 \mathrm{ug} / \mathrm{mL}$ & $10 \mathrm{~min}$ & $\begin{array}{l}\text { Murine } \\
\text { macrophage }\end{array}$ & LPS & NO & Inhibition & [62] \\
\hline Rhus verniciflua & Lignum & $\begin{array}{l}\text { Chloroform } \\
\text { ethyl acetate }\end{array}$ & $16.7 \mathrm{ug} / \mathrm{mL}$ & $10 \mathrm{~min}$ & $\begin{array}{l}\text { Murine } \\
\text { macrophage }\end{array}$ & LPS & NO & Inhibition & [62] \\
\hline
\end{tabular}

Ginkgo Standardized-24\% flavonoid glycosides, 6\% terpenoids; LPS, lipopolysaccharide; PMA, phorbol myristate acetate. 
of IL-8 production and signal transmission, 109 inhibition of TNF- $\alpha, 107$ inhibition of the transcription factor $\mathrm{NF}_{\mathrm{K}} \mathrm{B}, 110$ and the scavenging effects and induction of antioxidant enzymes. 111 Of interest, the NO pathways link turmeric to all three activities: anti-inflammatory, antioxidant and anticarcinogenic activity.

Since nitric oxide is found to be elevated when inflammation is present, the ability of turmeric to inhibit nitric oxide is a possible partial explanation for its anti-inflammatory properties. In the course of screening Asian anti-inflammatory herbs for inhibitory activity of nitric oxide synthesis, a crude extract of Curcuma zedoaria showed significant inhibitory activity as compared to other herbs. The crude methanolic extract of Curcuma zedoaria was found to inhibit the synthesis of nitric oxide by $78 \%$ in vitro. .80

Nitric oxide inhibition may also be a causative factor in the anticarcinogenic activity of turmeric and curcumin. iNOS is overexpressed in colonic tumors of humans and also in murine models. In an animal study on colon tumor development, curcumin was found to inhibit colonic aberrant crypt foci formation by $45 \%(\mathrm{P}<0.001)$, an indicator of its anticarcinogenic and iNOS inhibitory activity. ${ }^{112}$

There is evidence to suggest that the antioxidant activity of turmeric and curcumin are also linked to nitric oxide modulation. The effects of curcumin on the nitric oxide pathway in cardiac tissue and cultured cells were studied on rats with induced diabetes. One month of induced diabetes caused an upregulation of both eNOS and iNOS mRNA levels in the heart. Treatment of the diabetic rats with curcumin reduced eNOS and iNOS levels in association with reduced oxidative DNA and protein damage. 113

Many medicinal plants, which influence the NOS system also contain reasonable concentrations of folate.114 Serum homocysteine concentrations, which are reduced by folate, are suspected to cause the accumulation of asymmetrical dimethylarginine (ADMA). ADMA impairs NO synthesis and therefore accelerates atherosclerosis. ${ }^{115}$ Hence the combination of NOS modulating constituents in the reviewed plants and the nutrient folate may additively or synergically act against atherosclerosis.

Besides secondary metabolites, primary metabolites of plants have also shown an effect on NO. For example, $\alpha$-linolenic acid has been shown to lower the release of eicosanoids and NO from human aortic endothelial cells. ${ }^{116}$ Arginine, another primary metabolite of plants and the substrate of NOS, yields NO as a product. Clinical trials on patients with coronary or peripheral arterial disease have demonstrated increases in walking distance, exercise capacity, and quality of life, with a decrease in symptoms when supplemented with arginine. ${ }^{31,32,34}$
This suggests that arginine rich foods, which generally come from plant-based proteins, may have positive NO activity resulting in beneficial cardiovascular effects.117,118 This provides yet another pathway, in addition to folate and secondary metabolites, by which medicinal plants may have an influence on vascular dynamics. NO signaling represents a fundamental process in the body that appears to be modulated by a large number of plants. While this is pharmacologically intriguing, it frames a larger question about the role of phytochemistry in mammalian physiology. Considered from an evolutionary time scale, NO activity appears to have been modulated by plant compounds for millions of years. While the study of NO modulation by phytochemicals is enticing and deserves further investigation, future research should also consider the effects on physiological processes when NO signaling is not routinely modulated due to decreased phytochemical intake.119 This may offer further insights into chronic disease processes.

\section{Conclusions}

The reviewed data demonstrate that many medicinal plants have effects on the nitric oxide pathways. Considering the observations made by traditional healers, modern phytotherapists, and laboratory researchers regarding the reviewed plants, the beneficial activity of these medicinal plants may be partially due to effects on the nitric oxide pathways. Many of these reviewed medicinal plant species may be appropriate in nitric oxide based conditions. Further studies are needed to clarify the clinical therapeutics of these chemically complex remedies.

\section{References}

1. Furchgott RF, Zawadzki JV. The obligatory role of endothelial cells in the relaxation of arterial smooth muscle by acetylcholine. Nature 1980;288:373-6.

2. Vallance P. Importance of asymmetrical dimethylarginine in cardiovascular risk. Lancet 2001;358:2096-7.

3. Tuteja N, Chandra M, Tuteja R, Misra MK. Nitric oxide as a unique bioactive signaling messenger in physiology and pathophysiology. J Biomed Biotechnol 2004;4:227-37.

4. Berdeaux A. Nitric oxide: an ubiquitous messenger. Fundam Clin Pharmacol 1993;7:401-11.

5. Thomas DD, Ridnour LA, Isenberg JS, et al. The chemical biology of nitric oxide: Implications in cellular signaling. Free
Radic BiolMed 2008;45:18-31.

6. Gautier-Sauvigne S, Colas D, Parmantier P, et al. Nitric oxide and sleep. Sleep Med Rev 2005;9:101-13.

7. Moncada S. The L-arginine: nitric oxide pathway, cellular transduction and immunological roles. Adv Second Messenger Phosphoprotein Res 1993;28: 97-9.

8. Thippeswamy T, McKay JS, Morris R, et al. Glial-mediated neuroprotection: evidence for the protective role of the NOcGMP pathway via neuron-glial communication in the peripheral nervous system. Glia 2005;49:197-210.

9. Ballard SA, Gingell CJ, Tang $\mathrm{K}$, et al. Effects of sildenafil on the relaxation of human corpus cavernosum tissue in vitro and on the activities of cyclic nucleotide phosphodiesterase isozymes. J Urol 1998;159:2164-71.

10. Cerquetti MC, Goren NB, Ropolo AJ, et al. Nitric oxide and apoptosis induced in Peyer's patches by attenuated strains of Salmonella enterica serovar Enteritidis. Infect Immun 2002;70:964-9.

11. Moncada S, Higgs A. The L-argininenitric oxide pathway. N Engl J Med 1993; 329:2002-12.

12. Li H, Poulos TL. Structure-function studies on nitric oxide synthases. J Inorg Biochem 2005;99:293-305.

13. Forstermann U, Closs EI, Pollock JS, et al. Nitric oxide synthase isozymes. Characterization, purification, molecular cloning, and functions. Hypertension 1994;23:1121-31.

14. Kubes P, McCafferty DM. Nitric oxide and intestinal inflammation. Am J Med 2000;109:150-8.

15. Hofmann H, Schmidt HH. Thiol dependence of nitric oxide synthase. Biochemistry 1995;34:13443-52.

16. Mayer B, John M, Bohme E. Purification of a $\mathrm{Ca} 2+/$ calmodulin-dependent nitric oxide synthase from porcine cerebellum. Cofactor-role of tetrahydrobiopterin. FEBS Lett 1990;277:215-9.

17. Stuehr DJ, Kwon NS, Nathan CF. FAD and GSH participate in macrophage synthesis of nitric oxide. Biochem Biophys Res Commun 1990;168:558-65.

18. Bojunga J, Dresar-Mayert B, Usadel KH, et al. Antioxidative treatment reverses imbalances of nitric oxide synthase isoform expression and attenuates tissuecGMP activation in diabetic rats. Biochem Biophys Res Commun 2004; 316:771-80.

19. Thilakawardhana S, Everett DM, Murdock PR, et al. Quantification of apolipoprotein $\mathrm{E}$ receptors in human brain-derived cell lines by real-time polymerase chain reaction. Neurobiol Aging 
2005;26:813-23.

20. Marcourakis T, Bahia VS, Kawamoto EM, et al. Apolipoprotein E genotype is related to nitric oxide production in platelets. Cell biochem funct 2008;26:852-8.

21. Mather KJ, Lteif A, Steinberg HO, Baron AD. Interactions between endothelin and nitric oxide in the regulation of vascular tone in obesity and diabetes. Diabetes 2004;53:2060-6.

22. Hemmrich K, Thomas GPL, Abberton KM, et al. Monocyte chemoattractant protein1 and nitric oxide promote adipogenesis in a model that mimics obesity. Obesity 2007;15:2951-7.

23. Guzik TJ, Korbut R, Adamek-Guzik T. Nitric oxide and superoxide in inflammation and immune regulation. $\mathrm{J}$ Physiol Pharmacol 2003;54:469-87.

24. Bengmark S, Gianotti L. Nutritional support to prevent and treat multiple organ failure. World J Surg 1996;20:474-81.

25. Andrew PJ, Mayer B. Enzymatic function of nitric oxide synthases. Cardiovasc Res 1999;43:521-31.

26. Geller DA, Billiar TR. Molecular biology of nitric oxide synthases. Cancer Metastasis Rev 1998;17:7-23.

27. Ji H, Li H, Flinspach M, et al. Computer modeling of selective regions in the active site of nitric oxide synthases: implication for the design of isoformselective inhibitors. J Med Chem 2003; 46:5700-11.

28. Carr A, Frei B. The role of natural antioxidants in preserving the biological activity of endothelium-derived nitric oxide. Free Radic Biol Med 2000;28:1806-14.

29. Fraser GE. Diet and coronary heart disease: beyond dietary fats and low-density-lipoprotein cholesterol. Am J Clin Nutr 1994;59:1117S-23S.

30. Lissin LW, Oka R, Lakshmi S, Cooke JP. Isoflavones improve vascular reactivity in post-menopausal women with hypercholesterolemia. Vasc Med 2004;9:26-30.

31. Maxwell AJ, Anderson B, Zapien MP, Cooke JP. Endothelial dysfunction in hypercholesterolemia is reversed by a nutritional product designed to enhance nitric oxide activity. Cardiovasc Drugs Ther 2000;14:309-16.

32. Tangphao 0, Chalon S, Coulston AM, et al. L-arginine and nitric oxide-related compounds in plasma: comparison of normal and arginine-free diets in a 24 -h crossover study. Vasc Med 1999;4:27-32.

33. Wells BJ, Mainous AG 3rd, Everett CJ. Association between dietary arginine and C-reactive protein. Nutrition 2005;21:125-30.

34. West SG, Likos-Krick A, Brown P, Mariotti F. Oral L-arginine improves hemodynamic responses to stress and reduces plasma homocysteine in hypercholesterolemic men. J Nutr 2005;135: 212-7.

35. Wang J, Mazza G. Effects of anthocyanins and other phenolic compounds on the production of tumor necrosis factor alpha in LPS/IFN-gamma-activated RAW 264.7 macrophages. J Agric Food Chem 2002;50:4183-9.

36. Spelman K, Burns JJ, Nichols D, et al. Modulation of Cytokine Expression by Traditional Medicines: A Review of Herbal Immunomodulators. Alt Med Rev 2006;11:128-50.

37. Calixto JB, Otuki MF, Santos ARS. Antiinflammatory compounds of plant origin. Part I. Action on arachidonic acid pathway, nitric oxide and nuclear factor kappa B (NF-kappa B). Planta Med 2003;69:973-83.

38. Spelman K, Aldag R, Hamman A, et al. Traditional herbal remedies that influence cell adhesion molecule activity. Phytother Res 2011;25:473-83.

39. Burns JJ, Zhao L, Taylor EW, Spelman K. The influence of traditional herbal formulas on cytokine activity. Toxicology 2010;278:140-59.

40. Spelman K, Duke JA, BogenschutzGodwin MJ. The Synergy Principle in Plants, Pathogens, Insects, Herbivores and Humans. In: Kaufman PB (ed.) Natural products from plants. CRC Press, Boca Raton, Flarida, 2006:475-501.

41. Islam J, Carter R. Use of Echinacea in upper respiratory tract infection. South Med J 2005;98:311-8.

42. Guo JS, Cheng CL, Koo MWL. Inhibitory effects of Centella asiatica water extract and asiaticoside on inducible nitric oxide synthase during gastric ulcer healing in rats. Planta Med 2004;70:1150-4.

43. Kim YH, Ko WS, Ha MS, et al. The production of nitric oxide and TNF-alpha in peritoneal macrophages is inhibited by Dichroa febrifuga Lour. J Ethnopharmacol 2000;69:35-43.

44. Goel V, Chang C, Slama J, et al. Echinacea stimulates macrophage function in the lung and spleen of normal rats. J Nutr Biochem 2002;13:487.

45. Ganju L, Karan D, Chanda S, et al. Immunomodulatory effects of agents of plant origin. Biomed Pharmacother 2003;57:296-300.

46. Kwan CY, Zhang WB, Deyama T, Nishibe S. Endothelium-dependent vascular relaxation induced by Eucommia ulmoides Oliv. bark extract is mediated by NO and EDHF in small vessels. Naunyn Schmiedebergs Arch Pharmacol 2004;369:206-11.

47. Rawal A, Muddeshwar M, Biswas S. Effect of Rubia cordifolia, Fagonia creti- ca linn, and Tinospora cordifolia on free radical generation and lipid peroxidation during oxygen-glucose deprivation in rat hippocampal slices. Biochem Biophys Res Commun 2004;324:588-96.

48. Ferreira AP, Soares GL, Salgado CA, et al. Immunomodulatory activity of Mollugo verticillata L. Phytomedicine 2003;10:154-8.

49. Makino T, Ono T, Muso E, et al. Suppressive effects of Perilla frutescens on spontaneous IgA nephropathy in ddY mice. Nephron 1999;83:40-6.

50. Medeiros IA, Santos MRV, Nascimento NMS, Duarte JC. Cardiovascular effects of Sida cordifolia leaves extract in rats. Fitoterapia 2006;77:19-27.

51. Ko WS, Kim YH, Yoon JW, et al. Inhibitory effect of Spirodela polyrhixa on the secretion of NO in LPS-stimulated macrophages. Am J Chin Med 2004;32: 65-73.

52. Lee KY, Jeon YJ. Macrophage activation by polysaccharide isolated from Astragalus membranaceus. Int Immunopharmacol 2005;5:1225-33.

53. Punturee K, Wild CP, Vinitketkumneun U. Thai medicinal plants modulate nitric oxide and tumor necrosis factor-alpha in J774.2 mouse macrophages. J Ethnopharmacol 2004;95:183-9.

54. Chu CY, Lee MJ, Liao CL, et al. Inhibitory effect of hot-water extract from dried fruit of Crataegus pinnatifida on lowdensity lipoprotein (LDL) oxidation in cell and cell-free systems. J Agric Food Chem 2003;51:7583-8.

55. Chung HS, Jeong HJ, Kim JS, et al. Activation of inducible nitric oxide synthase by Euonymus alatus in mouse peritoneal macrophages. Clin Chim Acta 2002;318:113-20.

56. Chung HS, Jeong HJ, Han MJ, et al. Nitric oxide and tumor necrosis factoralpha production by Ixeris dentata in mouse peritoneal macrophages. J Ethnopharmacol 2002;82:217-22.

57. Tai J, Cheung S, Chan E, Hasman D. In vitro culture studies of Sutherlandia frutescens on human tumor cell lines. $\mathrm{J}$ Ethnopharmacol 2004;93:9-19.

58. Wang SY, Chang HN, Lin KT, Antioxidant properties and phytochemical characteristics of extracts from Lactuca indica. J Agric Food Chem 2003;51:1506-12.

59. Chung HS, Kang M, Cho C, et al. Inhibition of lipopolysaccharide and interferon-gamma-induced expression of inducible nitric oxide synthase and tumor necrosis factor-alpha by Lithospermi radix in mouse peritoneal macrophages. J Ethnopharmacol 2005; 102:412-7.

60. Mahmood MS, Gilani AH, Khwaja A, et al. 
The in vitro effect of aqueous extract of Nigella sativa seeds on nitric oxide production. Phytother Res 2003;17:921-4.

61. Chung HS, Jeong HJ, Hong SH, et al. Induction of nitric oxide synthase by Oldenlandia diffusa in mouse peritoneal macrophages. Biol Pharm Bull 2002;25: 1142-6.

62. Kim IT, Park YM, Shin KM, et al. Antiinflammatory and anti-nociceptive effects of the extract from Kalopanax pictus, Pueraria thunbergiana and Rhus verniciflua. J Ethnopharmacol 2004;94: 165-73.

63. Mehrotra S, Mishra KP, Maurya R, et al. Anticellular and immunosuppressive properties of ethanolic extract of Acorus calamus rhizome. Int Immunopharmacol 2003;3:53-61.

64. Chiang YM, Chuang DY, Wang SY, et al. Metabolite profiling and chemopreventive bioactivity of plant extracts from Bidens pilosa. J Ethnopharmacol 2004; 95:409-19.

65. Pae HO, Oh GS, Choi BM, et al. Inhibitory effects of the stem bark of Catalpa ovata G. Don. (Bignoniaceae) on the productions of tumor necrosis factoralpha and nitric oxide by the lipopolisaccharide-stimulated RAW 264.7 macrophages. J Ethnopharmacol 2003;88: 287-91.

66. Saha K, Lajis NH, Israf DA, et al. Evaluation of antioxidant and nitric oxide inhibitory activities of selected Malaysian medicinal plants. J Ethnopharmacol 2004;92:263-7.

67. Napolitano DR, Mineo JR, de Souza MA, et al. Down-modulation of nitric oxide production in murine macrophages treated with crude plant extracts from the Brazilian Cerrado. J Ethnopharmacol 2005;99:37-41.

68. Song YS, Kim SH, Sa JH, et al. Antiangiogenic and inhibitory activity on inducible nitric oxide production of the mushroom Ganoderma lucidum. J Ethnopharmacol 200;90:17-20.

69. Choi EM, Hwang JK. Effects of methanolic extract and fractions from Litsea cubeba bark on the production of inflammatory mediators in RAW264.7 cells. Fitoterapia 2004;75:141-8.

70. Blonska M, Bronikowska J, Pietsz G, et al. Effects of ethanol extract of propolis (EEP) and its flavones on inducible gene expression in J774A.1 macrophages. J Ethnopharmacol 2004;91:25-30.

71. Hu C, Kitts DD. Dandelion (Taraxacum officinale) flower extract suppresses both reactive oxygen species and nitric oxide and prevents lipid oxidation in vitro. Phytomed 2005;12:588-97.

72. Banskota AH, Tezuka Y, Nguyen NT, et al.
DPPH radical scavenging and nitric oxide inhibitory activities of the constituents from the wood of Taxus yunnanensis. Planta Med 2003;69:500-5.

73. Grande S, Bogani P, De Saizieu A, et al. Vasomodulating potential of Mediterranean wild plant extracts. J Agric Food Chem 2004;52:5021-6.

74. Jun CD, Pae HO, Kim YC, et al. Inhibition of nitric oxide synthesis by butanol fraction of the methanol extract of Ulmus davidiana in murine macrophages. J Ethnopharmacol 1998; 62:129-35.

75. Ryu JH, Ahn H, Kim JY, Kim YK. Inhibitory activity of plant extracts on nitric oxide synthesis in LPS-activated macrophages. Phytother Res 2003;17: 485-9.

76. Engwerda CR, Andrew D, Murphy M, Mynott TL. Bromelain activates murine macrophages and natural killer cells in vitro. Cell Immunol 2001;210:5-10.

77. Chen YH, Dai HJ, Chang HP. Suppression of inducible nitric oxide production by indole and isothiocyanate derivatives from Brassica plants in stimulated macrophages. Planta Med 2003;69:696-700.

78. Koo HN, Hong SH, Seo HG, et al. Inulin stimulates NO synthesis via activation of PKC-alpha and protein tyrosine kinase, resulting in the activation of NF-kappaB by IFN-gamma-primed RAW 264.7 cells. J Nutr Biochem 2003;14:598-605.

79. Mendonca RR, Rodrigues IA, Alviano DS, et al. Leishmanicidal activity of polyphenolic-rich extract from husk fiber of Cocos nucifera Linn. (Palmae). Res Microbiol 2004;155:136-43.

80. Jang MK, Lee HJ, Kim JS, Ryu JH. A curcuminoid and two sesquiterpenoids from Curcuma zedoaria as inhibitors of nitric oxide synthesis in activated macrophages. Arch Pharm Res 2004;27: 1220-5.

81. Rininger JA, Kickner S, Chigurupati P, et al. Immunopharmacological activity of Echinacea preparations following simulated digestion on murine macrophages and human peripheral blood mononuclear cells. J Leukoc Biol 2000;68:503-10.

82. Stevenson LM, Matthias A, Banbury L, et al. Modulation of macrophage immune responses by Echinacea. Molecules 2005;10:1279-85.

83. Cheung F, Siow YL, Chen WZ, 0 K. Inhibitory effect of Ginkgo biloba extract on the expression of inducible nitric oxide synthase in endothelial cells. Biochem Pharmacol 1999;58:1665-73.

84. Kim GY, Choi GS, Lee SH, Park YM. Acidic polysaccharide isolated from Phellinus linteus enhances through the up-regulation of nitric oxide and tumor necrosis factor-alpha from peritoneal macrophages. J Ethnopharmacol 2004; 95: 69-76.

85. Wagner H. Synergy research: approaching a new generation of phytopharmaceuticals. Fitoterapia 2011;82:34-7.

86. Williamson EM. Synergy and other interactions in phytomedicines. Phytomedicine 2001;8:401-9.

87. Spelman K. "Silver Bullet" Drugs Vs. Traditional Herbal Remedies: Perspectives on Malaria. HG J Am Bot Counc 2009;84:44-55.

88. Halliwell B. Oxidative stress in cell culture: an under-appreciated problem? FEBS Letters 2003;540:3-6.

89. Mahady GB. Medicinal plants for the prevention and treatment of bacterial infections. Curr Pharm Des 2005;11:2405-27.

90. Cott J. Medicinal plants and dietary supplements: sources for innovative treatments or adjuncts: an introduction. Psychopharm Bull 1995;31:131-7.

91. Cotran RS, Kumar V, Collins T, Robbins SL. Robbins pathologic basis of disease. 6th ed. Saunders, Philadelphia, 1999.

92. Cook SP. Coronary artery disease, nitric oxide and oxidative stress: the "YinYang" effect - a Chinese concept for a worldwide pandemic. Swiss Med Wkly 2006;136:103-13.

93. Cooke JP. Is atherosclerosis an arginine deficiency disease? J Investig Med 1998; 46:377-80.

94. Bland JS. Oxidants and antioxidants in clinical medicine: Past, present and future potential. J Nutr Environ Med 1995;5:255-80.

95. Achike FI, Kwan C-Y. Nitric oxide, human diseases and the herbal products that affect the nitric oxide signalling pathway. Clin Exp Pharmacol Physiol 2003;30:605-15.

96. Ou B, Huang D, Hampsch-Woodill M, Flanagan JA. When east meets west: the relationship between yin-yang and antioxidation-oxidation. FASEB J 2003; 17:127-9.

97. Sun LZ, Currier NL, Miller SC. The American coneflower: a prophylactic role involving nonspecific immunity. J Altern Complement Med 1999;5:437-46.

98. Schuberth HJ, Riedel-Caspari G, Leibold W. Flow Cytometric Testing of Immunological Effects of a Phytomedicinal Combination (EquiMun) and its Compounds on Bovine Leucocytes. J Vet Med A 2002;49:291-8.

99. Heesen W. Unspezifische Behandlungsmoglichkeiten bei tuberkulosen Erkrankungen. Erfahrungsheilkunde 1964;13:210-17.

100. Goel V, Chang C, Slama JV, et al. Alkylamides of Echinacea purpurea stim- 
ulate alveolar macrophage function in normal rats. Int Immunopharmacol 2002;2:381-7.

101. Raduner S, Majewska A, Chen J-Z, et al. Alkylamides from Echinacea Are a New Class of Cannabinomimetics: Cannabinoid Type 2 Receptor-Dependent and Independent Immunomodulatory Effects. J Biol Chem 2006;281:14192-206.

102. Sasagawa M, Cech NB, Gray DE, et al. Echinacea alkylamides inhibit interleukin-2 production by Jurkat T cells. Int Immunopharmacol 2006;6:1214-21.

103. Gertsch J, Schoop R, Kuenzle U, Suter A. Echinacea alkylamides modulate TNFalpha gene expression via cannabinoid receptor CB2 and multiple signal transduction pathways. Febs Lett 2004;577: 563-9.

104. Randolph RK, Gellenbeck K, Stonebrook $\mathrm{K}$, et al. Regulation of human immune gene expression as influenced by a commercial blended Echinacea product: Preliminary studies. Exp Biol Med 2003; 228:1051-6.

105. Lao CD, Ruffin MTt, Normolle D, et al. Dose escalation of a curcuminoid formulation. BMC Complementary and Alternative Medicine. 2006;6:10.

106. Snow J, Spelman K. The Influence of Bitter, Aromatic and Pungent Herbs on Gut Function. In: Mullin GE, Matarese LE, Palmer M (eds.) Gastrointestinal and liver disease nutrition desk reference. Taylor and Francis, Boca Raton, Florida, USA, 2011.

107. Chan MM. Inhibition of tumor necrosis factor by curcumin, a phytochemical. Biochem Pharmacol 1995;49:1551-6.

108. Kim JE, Kim AR, Chung HY, et al. In vitro peroxynitrite scavenging activity of diarylheptanoids from Curcuma longa. Phytother Res 2003;17:481-4.

109. Hidaka H, Ishiko T, Furuhashi T, et al. Curcumin inhibits interleukin 8 production and enhances interleukin 8 receptor expression on the cell surface:impact on human pancreatic carcinoma cell growth by autocrine regulation. Cancer 2002; 95:1206-14.

110. Thangapazham RL, Sharma A, Maheshwari RK. Multiple molecular targets in cancer chemoprevention by curcumin. AAPS Journal 2006;8:E443-9.

111. Okada K, Wangpoengtrakul C, Tanaka T, et al. Curcumin and especially tetrahydrocurcumin ameliorate oxidative stress-induced renal injury in mice. $\mathrm{J}$ Nutr 2001;131:2090-5.

112. Rao CV, Kawamori T, Hamid R, Reddy BS. Chemoprevention of colonic aberrant crypt foci by an inducible nitric oxide synthase-selective inhibitor. Carcinogenesis 1999;20:641-4.

113. Farhangkhoee H, Khan ZA, Chen S, Chakrabarti S. Differential effects of cur- cumin on vasoactive factors in the diabetic rat heart. Nutr Meta 2006;3:27.

114. Duke J. Dr. Duke's Phytochemical and Ethnobotanical Databases. 2008 April 10, 2005 cited 2008 July 15.; Available from: http://www.ars-grin.gov/duke/

115. Stuhlinger MC, Tsao PS, Her JH, et al. Homocysteine impairs the nitric oxide synthase pathway: role of asymmetric dimethylarginine. Circulation 2001;104: 2569-75.

116. Eder K, Schleser S, Becker K, Korting R. Conjugated linoleic acids lower the release of eicosanoids and nitric oxide from human aortic endothelial cells. J Nutr 2003;133:4083-9.

117. Krajcovicova-Kudlackova M, Babinska K, Valachovicova M. Health benefits and risks of plant proteins. Bratislavske lekarske listy 2005;106:231-4.

118. Ni W, Tsuda Y, Takashima S, Sato H, Sato M, Imaizumi K. Anti-atherogenic effect of soya and rice-protein isolate, compared with casein, in apolipoprotein Edeficient mice. Br J Nutr 2003;90:13-20.

119. Spelman K. Ecological Pharmacology: From Gaia to pharmacology. In: Micozzi MS, (ed.) Fundamentals of complementary and alternative medicine. Saunders/Elsevier, St. Louis, MO, USA, 2010, p 624. 